\title{
Ethos, Embodiment, Psychosis: Losing One's Home-Identity Stakes
}

\author{
Michèle Gennart
}

\subsection{Introduction}

The background to this chapter is provided by phenomenological work on the apprehension of the body by Erwin Straus [1] and on the constitution of identity by Paul Ricœur [2]. This work suggests an understanding of the body as a dimension of the self. The body participates in the self-affection by which the subject's identity is spontaneously constituted, albeit still below any conscious project or act of will. As soon as I am awake, move, and feel the world around me, I also feel myself as living this experience. Any bodily experience as it is lived as "mine" supports the feeling of "being oneself" (ipseity). Bringing ourselves into the world and inserting ourselves into an inter-corporeality, our body "anticipates" us in the process of building our sense of subjective identity [3].

According to this approach, our bodily condition is the bearer of an "intersubjective pre-identity," characterized by ethnic particularities, by a "family tune," but also by customs and habits, ways of trading with the world, of being with each other, which outline the main features of the ethos, of the cultural atmosphere, in which we have developed. As much in its appearance as by all the know-how and habits that it carries, our body is thus charged with sketches of identity of which we are not necessarily aware but which support our work of reflection and more deliberate choices and values about what we are and wish to become.

It is therefore through our living body, feeling and moving, that we are primarily present in the surrounding world as well as to ourselves, in what Erwin Straus calls a pre-reflexive pathic communication [1]. Now, different crises can affect this knot through which our body exerts its mediating function between "self" and world. Ruptures of belonging in migration or exile are one form of this rupture. By losing

M. Gennart $(\triangle)$

Centre de Recherches Familiales et Systémiques, Neuchâtel, Switzerland

e-mail: gennart@bluewin.ch 
the overall familiarity, the tuning, and the "syntony" that was created with the surrounding world and its singular culture, both sensitive and invisible, the subject is exposed to an identity discordance that may require considerable work of reappropriation of her or him. Not only speaking and understanding the language of the other but also less obvious differences-ways of moving socially, tastes, sounds, landscapes, and atmospheres. All these aspects can be disconcerting and give the migrant subject the feeling of being "maladjusted" and "lost." In psychotic disorders, something of the very knotting of "self to the world" is affected in a more radical way [4]; one's own body seems no longer able to play its full natural or evident mediating function of bringing the subject into the world, and, in the same movement, to collect it "at home."

These considerations are illustrated by the following story in which "Tania Z" (not her real name), a woman of Portuguese descent, feels "betrayed" by her parents in relation to a central cultural value of her native country-namely the safeguarding and trans-generational transmission of the family home. She succumbs to a serious psychic crisis. Showing herself as more loyal than her parents to the values of their native country, but beyond all "reasonableness," she mobilizes a singular way of inhabiting the home in such a way that the latter exercises a function of self-shelter analogous to that of the own body. Her story departs from common sense-her family and friends do not understand her at all. Indeed, she puts into words processes that are usually implicit: those that allow the surrounding world to be presented as a livable, familiar space, making it possible for the self to exist. Her story thus allows us to understand something of these mysterious conditions of emergence, maintenance, or destruction of the human self [5].

\subsection{The Story of Tania Z: Thrown Out of Home}

Tania Z, a social worker in her fifties of Portuguese descent, was referred by her general practitioner (GP) for functional symptoms and an anxious state that compromised her ability to work and had led her to become increasingly isolated. The GP insisted that she should undergo a joint psychotherapeutic treatment, which she did not consent to easily. In her view, the problem was not psychological; it had to do with her body and her living space. She accepted nonetheless to meet with us and to give her suffering a narrative configuration.

Her story was that she had developed a severe anxious depression, with melancholic tendencies, when she learned that she was to be forced to leave the family home where she had lived most of her life, first with her parents, then by moving into her own apartment right above them.

Her parents, pressured by the real estate developers who were planning to demolish and rehabilitate the whole neighborhood, had accepted an offer to sell their house. Tania was given no choice in the matter. She was distressed by this situation, which she considered a betrayal by her parents: a betrayal of a central 
cultural value of their country of origin-namely the transgenerational handover of the family home-and a betrayal of the family spirit itself.

Prior to this, her parents had also chosen to be cremated at their death: this was also against family and cultural traditions. They did not want to burden their children and had organized their funeral themselves. Even then, Tania had felt abandoned: "It was terrifying for me. Even in death, they will abandon me. They did not even consider that I would end up alone in a grave!"

The "ultimate home"- the one that could have been shared by the family across time and generations-was therefore wiped out even before the current home was lost. This first decision taken by Tania's parents had already come as a blow to the family affiliation. The second, the sale of the house, definitely severed the integrity of the transgenerational connection. Tania thought she played an important and appreciated role for her parents by staying close to them; she would stop by on her way home from work, make sure they did not need anything, and advise them when they needed help. And then, they go and decide to move into a small apartment on their own, shattering the mission to which she had devoted herself years ago. The same goes for another implicit mission she had taken on: taking care of the house once the parents could no longer manage it. It was as if the fundamental beliefs that held her world together were being torn apart one after the other.

She appeared inhabited by a terrible indignation toward her parents and was ready to break off contact with them. However, the most intense suffering for her seemed to lie in the loss of the house, which she experienced as an actual ripping apart of her own being. "The day I will close the door of the house," she would say, "I will die. Or I will survive, but my spirit will no longer be." Losing her house therefore exposed her to the threat of losing her life or her spirit-the two possible forms of destruction of the self.

After a few months of acute apprehension, she managed to move, but her new living space was not well adapted to her. It had, for example, big windows that upset her: "Ifeel projected into an outside that doesn't belong to me. It makes no sense to me." She could not help hanging around the family house, picking herbs from the garden, with nostalgia, incomprehension, and heartbreak. Then, one day she found that there were other people occupying the house as it awaited demolition; she was distraught_- "it is like a violation"-and had to hold herself back from violent aggression toward the intruders.

The next dreaded deadline was the demolition of the house-which she was not sure she would survive: "I don't know if I will be able to assume the physical destruction of the house." Through these unusual terms, Tania speaks of the surprising alliance by which our own self is linked to that of a place. She has become the guardian of the house that protected her, and its destruction feels like her own. "When I think about it," she says, "it terrorizes me. 'One day will be the last day'. It's so surreal that I am unable to put it into something real, concrete. It is definite, there is no turning back."

Tania thus describes with sharp clarity her diffracted experience of reality. On one hand, she maintains an access, which is intact, to objective reality, where things and people remain partes extra partes. Yet at the same time, she is experiencing a 
"surreal" dimension, which she cannot reconcile with concrete reality, and which seems to touch the very conditions of emergence and disaster of that reality for us as human beings. This second dimension refers to the affective or pathic juncture that determines if we have (or have not) a tie to the world that we can (or cannot) be in, or find our place in it. This very alliance is shattered for Tania Z. who, with her house, loses her home and her presence in the world.

She is one with the house, linked by mutual intimacy and protection. The destruction of this anchor leaves her exposed to a preoccupying strangeness, a wandering, and a lack of meaning. Her new apartment feels like a "warehouse" where her things are laid down; "I feel lost in this place. It doesn't suit me. What do I do now? That's where I'm at; it's totally surreal. There is no sense to it, it is attached to nothing. I am floating. I stay with my friend a bit, I stay here a bit. But when I'm here, I'm not. I don't recognize my things. There are no roots. I miss the house. I obsess about returning there. I don't have a home anymore."

The crisis that first affected her living space is reflected directly in her own body space. She floats, feels like a robot. She is worried about a series of neurovegetative symptoms-loss of appetite, vertigo, and tremors-which make her think she has a potentially fatal disease that has not yet been diagnosed. She pressed her GP to arrange various examinations to confirm her sense of imminent destruction of the self. She has lost her love of life, has lost weight, feels numb, old, and without bearings.

\subsection{Values Arising}

Tania Z did not present florid psychotic symptoms (such as delusions or hallucinations) but nevertheless presents the structure of melancholic experience as described by phenomenological psychiatrists such as Tellenbach [6], with alteration of the basic continuity of the self. Her clinical situation thus sheds particular light on the special role of places, especially the home, with regard to human health and illness. The home concerns, at the same time, one's own body, its potential as oneself and its relation to past and future generations.

Tania's experience, like that of many other patients, gives us, first of all, an insight into the strong link between one's own body and the enclosing home's space. This could be the space in a room or any corner of the world that feels like home. Duplicating the body in a certain way, as a second envelope of the self, as a world's skin around the physical skin, the "home" is an eminent form of space that allows us to gather ourselves together and to become open to other people.

"The non-I that protects I" as Bachelard [7, p. 5] puts it, the house constitutes a transitional space between the "I" and the "other," a space to which we connect ourselves, under the protection of which we can relax and have the confidence to go and explore the world, where we allow ourselves to encounter others. And like the transitional phenomenon defined by Winnicot [8], the home or the "special place" contributes to what "contains" us; it supports our-humanly fallible-experience of continuity and integrity. As Bachelard [7, p. 7] comments, "In the life of a man, the 
house thrusts aside contingencies, its councils of continuity are unceasing. Without it, man would be a dispersed being. It maintains him through the storms of the heavens and through those of life. It is body and soul. It is the human being's first world." The stability of a home is constitutive of what I would happily call our "psychosomatic foundations."

Tania's story also highlights the essentially intersubjective nature of the home. The so-called familiar space is first and foremost the space where our family lives, the space that our "loved ones" have made safe and secure for us. The newborn's welcome into the world is mediated through safe and secure places that provide, in cultural form, an analogue of the protection provided by the physical body. Our connection with the physical space that becomes our own is also mediated through our relations with others. The loss of familiar places, by exile, destruction or, as here, by forced sale, represents both a betrayal of our affiliations and a challenge to maintain our identity.

Psychosis, or as in Tania Z's story being in a state of psychotic vulnerability, by affecting one's security and sense of being oneself, leads to an increased risk of the person feeling "lost in the world," and maybe an increased need to be comforted by secure environments that protect the uncertain boundaries of the self. Tania feels abandoned, cast into the world alone by parents who agree to abandon the family home to housing developers. She lives in her body, in her psychosomatic consistency and identity, the loss and subsequent destruction of her "family home"under its double intersubjective and spatial aspect.

\subsection{Cultural Influences}

In the situation described, two cultural models collide: Tania's participative model where the house is part of the family, defining the identity and purposes of its inhabitants, and, on the other hand, the utilitarian model, where the house, a physical object without any essential connection to people, is a disposable financial asset.

Tania's positioning is in line with her culture of Portuguese origin where it would indeed be expected that the family home is passed from one generation to the next, that the children take care of aging parents and that all rest at their death in the same grave. His migrant parents have somehow abandoned the norms and values of the native culture in the native country. And this mutation of the reference values, which appears to her through a series of parents' uncommented decisions, deeply upsets her. As Alfred Kraus, quoted by Tellenbach [5], writes, "social changes in the sense of breaking with the norm or of a contradiction with the norm can engender (...) dangerous general conditions for persons with a melancholy structure."

Among her relatives, Tania finds herself alone in witnessing the essential link that can arise between a material space and a living person-a link that perhaps constitutes what we would call the "soul" of a place. She struggles to be heard, but has nonetheless something to teach us about the significance of the house in relation to our "earthly" human condition. As Ricoeur [2, p. 150] puts it: "In virtue of the mediating function of the body as one's own in the structure of being in the world, 
the feature of selfhood belonging to corporeality is extended to that of the world as it is inhabited corporeally." Our active body, that is to say our condition as beings who move and feel, is our first way to "be ourselves," to assert out identity. But our embodied identity is never "pure," it is affected by "otherness," by our surroundings, by a world in which our identity is always a little mingled and entwined. To recapitulate Ricoeur's way of putting it, this aspect of the self-identity of the body extends to the physical, inhabited world. The place we inhabit as our "home" (corner, house, and region) typically relates to this aspect of world marked by the "self." Equally, the space perceived as uninhabitable is a space of floating and wandering, where the subject no longer finds a place to "be." Tania speaks to us with rare insight of the link between the possibility of being oneself and finding shelter in the world.

This shelter, which involves the practice of building, is one of the most basic foundations of culture. "All really inhabited space, says Bachelard [7, p. 5], bears the essence of the notion of home." As Tania's story makes us aware, society has a responsibility to look after inhabited spaces, not just as material objects, but as places where people move in and establish themselves. The loss and destruction of their home, for the most vulnerable, risk destroying their sense of personal identity.

\subsection{Conclusions}

Losing her sense of family belonging, Tania desperately attaches herself to the walls of her house - which seem to her more reliable, which can't betray. Like Winnicot's "transitional space," her "home" corner has become like a last bulwark: the ultimate "other" that surrounds and offers shelter and protection. Tania tells us about the essential link that can form between a material space and a bodily person. Opened by all our senses to the otherness of a world, we have to find protection in our exposition to space. This protection engages the practice of inhabiting it. The contribution of the habitat to our identity, to our sense of continuity and integrity, goes mostly unnoticed. Certain critical events are nevertheless able to remind us of our vulnerable "terrestrial" condition.

Altering the safety, the "naturality" of being-oneself, psychosis, and psychotic vulnerability are associated with increased risk for the person feeling lost in the world. These may also imply increased need to support the uncertain boundaries of self through the mediation of protective environments. Tania Z's story thus graphically reminds us that we should take care to recognize the primordial role of shared spaces and, from the intersubjective point of view, of this fundamental quality of hospitality offered to the "lost" human.

Acknowledgements Thanks to the two colleagues who translated this text:

- Cristiana FORTINI, psychologist in charge of service, lecturer, Department of Addictions Medicine, Department of Psychiatry, Lausanne, Switzerland.

- Daniella ARDEL EPINEY, psychologist, Cantonal Service of Youth. Monthey-Switzerland. 


\subsection{Guide to Further Sources}

For a values-based account of the importance of home to well being see:

- K. W. M. (Bill) Fulford and Kathleen T. Galvin (2018) Values-based Practice: at Home with Our Values Chapter 23, pp. 230-240, in Kathleen T. Galvin (Ed) Routledge Handbook of Well-Being. London: Routledge.

For a further phenomenological account see:

- G. Stanghellini (2004) Deanimated bodies and disembodied spirits. Essays on the psychopathology of common sense. Oxford: Oxford University Press.

\section{References}

1. Straus E. The primary world of senses: a vindication of sensory experience. New York: Free Press of Glencoe; 1935/1963.

2. Ricoeur P. Oneself as another. Transl. by K. Blamey. Chicago: The University of Chicago Press; 1990/1992.

3. Gennart M. Corporéité et présence Jalons pour une approche du corps dans la psychose. Argenteuil: Le Cercle Herméneutique; 2011.

4. Fuchs T, Schlimme JE. Embodiment and psychopathology: a phenomenological perspective. Curr Opin Psychiatry. 2009;22(6):570-5.

5. Gennart M, Vannotti M. Espaces familiers et identité; quand l'espace propre est hanté... Thérapie Familiale. 2014;4:439-50.

6. Tellenbach H. Melancholy: history of the problem, endogeneity, typology, pathogenesis, clinical considerations. Transl. by Erling Eng. Pittsburgh: Duquesne University Press; 1961/1980.

7. Bachelard G. The poetics of space. Transl. by M. Jolias. Boston: Beacon Press; 1957/1994.

8. Winnicott DW. Transitional objects and transitional phenomena; a study of the first not-me possession. Int J Psychoanal. 1953;34:89-97.

Open Access This chapter is licensed under the terms of the Creative Commons Attribution 4.0 International License (http://creativecommons.org/licenses/by/4.0/), which permits use, sharing, adaptation, distribution and reproduction in any medium or format, as long as you give appropriate credit to the original author(s) and the source, provide a link to the Creative Commons license and indicate if changes were made.

The images or other third party material in this chapter are included in the chapter's Creative Commons license, unless indicated otherwise in a credit line to the material. If material is not included in the chapter's Creative Commons license and your intended use is not permitted by statutory regulation or exceeds the permitted use, you will need to obtain permission directly from the copyright holder.

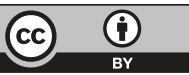

